\title{
PST-1: A Synthetic Small-Pore Zeolite that Selectively Adsorbs $\mathbf{H}_{2} * *$
}

\author{
Jiho Shin, Miguel A. Camblor, Hee Chul Woo, Stuart R. Miller, Paul A. Wright, and Suk Bong Hong*
}

The ability of zeolites to discriminate between molecules of different sizes and shapes has been long recognized. ${ }^{[1]}$ This ability legitimates their consideration as "Molecular Sieves" and has been the basis for many applications in catalysis and gas separation technologies. ${ }^{[2]}$ Some separation processes may also be based on specific host-guest interactions, rather than relying just on size/shape recognition. ${ }^{[3]}$ However, examples of selective adsorption of the smallest gases in zeolites are scarce. Here, we report on PST1 (POSTECH number 1), a zeolite that can adsorb only the smallest gases $\left(\mathrm{H}_{2}, \mathrm{He}\right.$, and $\mathrm{H}_{2} \mathrm{O}$ with Lennard-Jones (L-J) sizes of 2.89, 2.60 and $2.65 \AA$, respectively $\left.{ }^{[4]}\right)$, thus allowing discrimination from slightly larger molecules ( $\mathrm{Ar}$ and $\mathrm{CO}_{2}$ with L-J sizes of 3.40 and $3.30 \AA$ A, respectively). Furthermore, PST-1 is selective for $\mathrm{H}_{2}$ over $\mathrm{He}$, despite the smaller size of the latter.

PST-1 is a synthetic small-pore zeolite with the natrolite (NAT) topology $^{[5]}$ and a potassium gallosilicate composition. It can be obtained within a narrow window of synthesis conditions and contains a concentration of $\mathrm{Ga}$ atoms in tetrahedral $(\mathrm{T})$ positions $(\mathrm{Si} / \mathrm{Ga}=1.28)$ largely exceeding that typically found in synthetic gallosilicate NAT materials $(\mathrm{Si} / \mathrm{Ga} \geq 1.5) .{ }^{[6]}$ Its orthorhombic crystal structure, space group $F d d 2$, is remarkable for a natrolite with such a high heteroatom content, where $\mathrm{T}$ ordering is hindered by the Loewenstein rule. ${ }^{[7]}$ All known aluminosilicate NAT materials with $\mathrm{Si} / \mathrm{Al}<1.50$ are tetragonal and essentially completely disordered. However, PST-1 does present a noticeable, although modest, degree of ordering (the average long-range ordering coefficient, as defined by Alberti, is $S=0.10$, while 0 corresponds to complete disorder and 1 to complete order $)^{[8]}$ to which the observed symmetry lowering should be ascribed.

Dehydration of PST-1 occurs remarkably easily, even at $333 \mathrm{~K}$

[*] J. Shin, Prof. S. B. Hong

Department of Chemical Engineering and School of

Environmental Science and Engineering

POSTECH

Pohang 790-784 (Korea)

Fax: (+82) 54-279-8299

E-mail: sbhong@postech.ac.kr

Prof. M. A. Camblor

Instituto de Ciencia de Materiales de Madrid, CSIC 28049 Madrid (Spain)

Prof. H. C. Woo

Department of Chemical Engineering

Pukyong National University

Pusan 608-739 (Korea)

Dr. S. R. Miller, Dr. P. A. Wright

School of Chemistry

University of St. Andrews

St. Andrews KY16 9ST (UK)

[**] This work was supported by KOSEF (R0A-2007-00020050-0) and CDRSRC (16-2008-02-005-01). We thank PAL for synchrotron diffraction beam time.

Supporting information for this article is available on the WWW under http://www.angewandte.org or from the author. under vacuum to a residual pressure of $5 \times 10^{-3}$ Torr, or at $443 \mathrm{~K}$ at atmospheric pressure, and brings about a large shrinkage of the framework (ca. 16\%). This deformation mainly occurs along the $x$ and $y$ directions, with the unit cell edge along $z$ remaining almost constant $(-8.27,-8.39$ and $-0.02 \%$ variation of the $a, b$ and $c$ cell edges, respectively). The orthorhombic symmetry is lost in the dehydrated material (monoclinic B112), at variance with the orthorhombic $\left(I 2_{1} 2_{1} 2_{1}\right)$ to tetragonal $(I-42 d)$ transition observed upon dehydration in a very highly disordered Ga-rich natrolite. ${ }^{[6,8]}$

Despite its large Ga content, PST-1 is thermally stable up to at least $1073 \mathrm{~K}$ (Figure 1S), and it also withstands hydrothermal treatments up to at least $873 \mathrm{~K}$ in the presence of $10 \%$ water vapor. The easiness of dehydration and the high thermal and hydrothermal stability of PST-1 sharply contrast with the behavior of its more siliceous sodium gallosilicate natrolite counterparts with $\mathrm{Si} / \mathrm{Ga} \sim 1.6$ which require dehydration temperatures of $673 \mathrm{~K}$ or higher and become amorphous upon exposure to the laboratory humidity conditions. ${ }^{[6,8]}$ The high stability of PST-1 is unexpected because, typically in zeolites, the larger the concentration of trivalent latticesubstituting heteroatoms, which introduce a negative charge into the framework, the lower the thermal and hydrothermal stability of the material. ${ }^{[9]}$ The breaking and reorganization of Ga-O-Si bonds may require the presence of water, together with some thermal energy, being mediated through the formation of $\mathrm{Ga}-\mathrm{OH}$ and $\mathrm{Si}-\mathrm{OH}$ groups. As described above, however, "all" water in PST-1 is lost at a very low temperature, probably due to weaker interactions of $\mathrm{K}^{+}$ions with water molecules within the pores compared to smaller $\mathrm{Na}^{+}$. Hence, when the temperature becomes high enough to break bonds, PST-1 is completely dehydrated and its reorganization is no longer possible.

Following dehydration and framework volume shrinkage, the pores of PST-1 become extremely elongated, which should effectively block the pores to any molecule, even without considering pore blockage by $\mathrm{K}^{+}$ions in the channels (Figure 1). The free diameter along the short axis of the 9MR pores, for instance, is reduced to just $1.6 \AA$ in the dehydrated material (compared to the hydrated one). a)

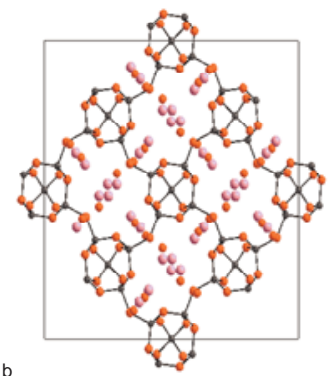

b)

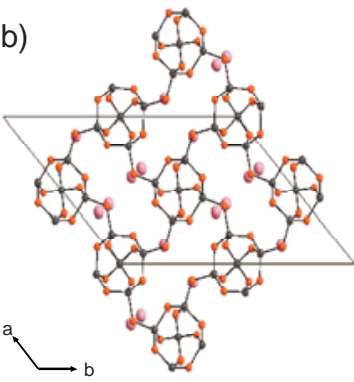

Figure 1. Refined structures of a) hydrated and b) dehydrated forms of PST-1. Purple spheres represent $\mathrm{K}^{+}$cations. 


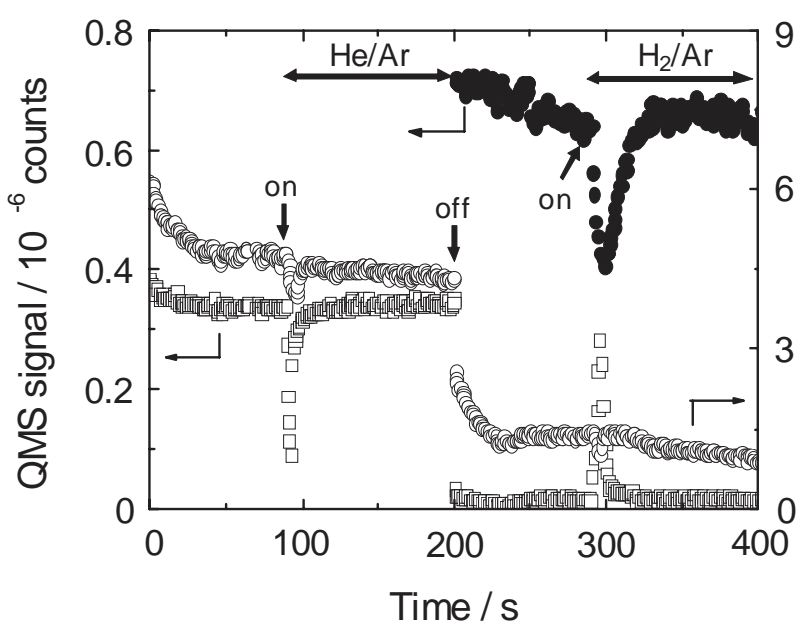

Figure 2. Breakthrough curves at $303 \mathrm{~K}, \mathrm{He}$ (open squares), $\mathrm{H}_{2}$ (closed circles), and $\mathrm{Ar}$ (open circles) for PST-1 first using a $\mathrm{He} / \mathrm{Ar}$ $(4: 96 \mathrm{v} / \mathrm{v})$ mixture and then $\mathrm{H}_{2} / \mathrm{Ar}(4: 96 \mathrm{v} / \mathrm{v})$ gas mixture. Mean value from triple parallel experiments (standard deviation $\sigma \leq 6 \%$ ) was adopted for each data point.

However, adsorption occurs in dehydrated PST-1. The breakthrough curves at $303 \mathrm{~K}$ for different mixtures of gases show that relatively small molecules such as $\mathrm{Ar}$ or $\mathrm{CO}_{2}$ are excluded from PST-1, while smaller molecules such as $\mathrm{H}_{2}$ and $\mathrm{He}$ are adsorbed (Figure 2S). The $\mathrm{H}_{2}$ and $\mathrm{He}$ sorption isotherms at $77 \mathrm{~K}$ up to 760 Torr partial pressure (Figure $3 \mathrm{~S}$ ) suggest a moderate selectivity for $\mathrm{H}_{2}$ at this temperature. On the contrary, the isotherms at $303 \mathrm{~K}$, in which PST-1 gives essentially zero Ar uptake, show similar uptakes $\left(\sim 0.5 \mathrm{~cm}^{3} \mathrm{~g}^{-1}\right)$ for both gases and hence no selectivity was expected. However, in competitive dynamic experiments (breakthrough curves) at the same temperature, PST-1 selectively adsorbs $\mathrm{H}_{2}$ over $\mathrm{He}$ in He-rich mixtures, with $\mathrm{H}_{2}$ being able to displace previously adsorbed He (Figure 2). This apparent contradiction is likely due to the static and dynamic nature of the adsorption isotherm and breakthrough curve experiments, respectively, and to the competitive character of the latter. The selectivity for $\mathrm{H}_{2}$ over inert and more symmetrical He cannot be due to size discrimination (L-J sizes of 2.89 and 2.60, respectively ${ }^{[4]}$ ), but suggest a specific interaction of PST-1 with $\mathrm{H}_{2}$ via polarization and quadrupolar interactions with its cationic centers. ${ }^{[10]}$

The adsorption properties of dehydrated PST-1 are remarkable for a material with such a small pore size, which is in addition crowded with $\mathrm{K}^{+}$ions. Powder XRD experiments (Figure 1S) reveal that the completely dehydrated PST-1 restores its original state within $0.5 \mathrm{~h}$ when rehydrated in ambient air. The easiness with which PST-1 expands and contracts reflects a very high degree of framework flexibility that is, in our view, central to its adsorption behavior.

Given the fast kinetics of the adsorption observed in the breakthrough curves, PST-1 could be a potential candidate for $\mathrm{H}_{2}$ and/or He separation processes based on pressure swing adsorption (PSA) or membrane technology. Because $\mathrm{H}_{2}$-rich streams are currently purified by high temperature processes based on Pd or $\mathrm{Pd} / \mathrm{Ag}$ membranes (a dissociative process selectively diffusing monatomic $\mathrm{H}$ at temperatures $>573 \mathrm{~K})^{[11]}$ or by PSA processes (selectively removing gases different from $\mathrm{H}_{2}$ on multi-component adsorbents) ${ }^{[12]}$ for example, PST-1 is attractive for low-temperature and low-cost membrane processes and for $\mathrm{H}_{2}$ enrichment by PSA technology of $\mathrm{H}_{2}$-poor mixtures. Of course, dehydrated PST-1 also adsorbs water and in competitive experiments water is selectively adsorbed over $\mathrm{H}_{2}$ (Figure $2 \mathrm{~S}$ ), so applications would be restricted to dried streams.

In summary, we have demonstrated that a synthetic potassium gallosilicate natrolite with a high $\mathrm{Ga}$ content $(\mathrm{Si} / \mathrm{Ga}=1.28)$ denoted PST-1 can selectively adsorb the smallest gases, especially $\mathrm{H}_{2}$, and hence discriminate them from slightly larger molecules like $\mathrm{Ar}$ or $\mathrm{CO}_{2}$. Because of the remarkable easiness of its dehydration and great (hydro)thermal stability, PST-1 could be a potential candidate for fast, selective $\mathrm{H}_{2}$ and/or He separation processes based on PSA or membrane technology.

\section{Experimental Section}

In a typical synthesis of PST-1, $3.75 \mathrm{~g}$ of gallium oxide (99.99+\%, Aldrich) and $19.95 \mathrm{~g}$ of $\mathrm{KOH}$ ( $45 \%$ aqueous solution, Aldrich) were first mixed in $5.59 \mathrm{~g}$ of $\mathrm{H}_{2} \mathrm{O}$. Then, the mixture was heated overnight at $373 \mathrm{~K}$. After cooling to room temperature, to this translucent solution, $15.00 \mathrm{~g}$ of colloidal silica (Ludox AS-40, DuPont) was added. The gel composition of the resulting mixture was $8.0 \mathrm{~K}_{2} \mathrm{O} \cdot 2.0 \mathrm{Ga}_{2} \mathrm{O}_{3} \cdot 10.0 \mathrm{SiO}_{2} \cdot 150 \mathrm{H}_{2} \mathrm{O}$. The final synthesis mixture was stirred at room temperature for 1 day, charged into Teflon-lined $45-\mathrm{mL}$ autoclaves, and heated at $423 \mathrm{~K}$ under rotation $(60 \mathrm{rpm})$ for 1.5 days. The solid product was recovered by filtration, washed repeatedly with water, and then dried overnight at room temperature (yield: $6.33 \mathrm{~g}, 14.3 \%$ based on the total weight of the synthesis mixture).

Synchrotron diffraction data for PST-1 in the as-made, hydrated form and when dehydrated at $373 \mathrm{~K}$ were collected on the $8 \mathrm{C} 2$ beamline equipped with a ceramic furnace of the Pohang Acceleration Laboratory (Pohang, Korea) using monochromated X-rays $(\lambda=1.54220 \AA)$. The detector arm of the vertical scan diffractometer consists of seven sets of soller slits, flat Ge(111) crystal analyzers, anti-scatter baffles, and scintillation detectors, with each set separated by $20^{\circ}$. The synchrotron diffraction data were obtained on the sample in flat plate mode, with a step size of $0.01^{\circ}$ and overlaps of $2^{\circ}$ to the next detector bank over the $2 \theta$ range $10-120^{\circ}$. Further details of the crystal structure analyses can be found in Supporting Information.

The gas separation properties of PST-1 were tested by breakthrough experiments at $303 \mathrm{~K}$ and atmospheric pressure using $\mathrm{H}_{2} / \mathrm{Ar}, \mathrm{He} / \mathrm{Ar}, \mathrm{H}_{2} / \mathrm{He}$ (4:96 v/v), $\mathrm{H}_{2} / \mathrm{CO}_{2} / \mathrm{He}(4: 4: 92 \mathrm{v} / \mathrm{v} / \mathrm{v})$, and $\mathrm{H}_{2} / \mathrm{H}_{2} \mathrm{O} / \mathrm{Ar}(2: 2: 96 \mathrm{v} / \mathrm{v} / \mathrm{v})$ gas mixtures. In a typical breakthrough experiment, $160.8 \mathrm{mg}$ of hydrated PST-1 were packed in a vertically placed fixed bed microreactor $(0.64 \mathrm{~cm}$ inner diameter), giving a sample height of $0.7 \mathrm{~cm}$, and then dehydrated in flowing He or Ar $\left(50 \mathrm{~cm}^{3} \mathrm{~min}^{-1}\right)$ at $723 \mathrm{~K}$ for $1 \mathrm{~h}$. After cooling to $303 \mathrm{~K}$, a gas mixture was passed through the dehydrated PST-1 $(150.0 \mathrm{mg})$ at the same temperature. The total gas flow at the quartz reactor inlet was fixed to 130 $\mathrm{cm}^{3} \mathrm{~min}^{-1}$ in order to maintain a gas hourly space velocity of $26,500 \mathrm{~h}^{-1}$. The intensities of each gas passing through the PST-1-packed reactor were monitored on a Hiden Analytical HPR20 gas analysis system detecting ion peaks at $m / z^{+}=2\left(\mathrm{H}_{2}\right), 4(\mathrm{He}), 18\left(\mathrm{H}_{2} \mathrm{O}\right), 40(\mathrm{Ar})$, and $44\left(\mathrm{CO}_{2}\right)$. The $\mathrm{H}_{2}$ and $\mathrm{He}$, and $\mathrm{Ar}$ sorption isotherms of PST-1 at 77 and $303 \mathrm{~K}$ were measured using a Mirae SI nanoPorosity-XG analyzer.

Received: ((will be filled in by the editorial staff))

Published online on ((will be filled in by the editorial staff))

Keywords: gas separation $\cdot$ hydrogen $\cdot$ zeolites $\cdot$ PST-1

[1] R. M. Barrer, Nature 1947, 159, 508

[2] J. D. Sherman, Proc. Natl. Acad. Sci. USA 1999, 96, 3471-3478.

[3] J. F. Kirner (Air Products), US-A 5268023, 1993.

[4] D. W. Breck, Zeolite Molecular Sieves, Wiley, New York, 1974, p. 636.

[5] Ch. Baerlocher, L. B. McCusker, Database of Zeolite Structures: http://www.iza-structure.org/databases/.

[6] S. B. Hong, S. H. Lee, C.-H. Shin, A. J. Woo, L. J. Alvarez, C. M. Zicovich-Wilson, M. A. Camblor, J. Am. Chem. Soc., 2004, 126, 13742-13751.

[7] A. Alberti, G. Cruciani, I. Dauru, Eur. J. Mineral. 1995, 7, 501-508. 
[8] H. H. Cho, S. H. Kim, Y. G. Kim, Y. C. Kim, H. Koller, M. A. Camblor, S. B. Hong, Chem. Mater. 2000, 12, 2292-2300.

[9] R. Szostak, Stud. Sur. Sci. Catal. 2001, 137, 261-297.

[10] A. Zecchina, S. Bordiga, J. G. Vitillo, G. Ricchiardi, C. Lamberti, G. Spoto, M. Bjørgen, K. P. Lillerud, J. Am. Chem. Soc., 2005, 127, 6361-6366.
[11] N. W. Ockwig, T. M. Nenoff, Chem. Rev. 2007, 107, 4078-4110.

[12] A. M. Ribeiro, C. A. Grande, F. V. S. Lopes, J. M. Loureiro, A. E. Rodrigues, Chem. Eng. Sci. 2008, 5258-5273. 


\section{Entry for the Table of Contents}

\section{Gas Separation}

Jiho Shin, Miguel A. Camblor, Hee Chul Woo, Stuart R. Miller, Paul A. Wright, and Suk Bong Hong*

$$
\text { Page - Page }
$$

PST-1: A Synthetic Small-Pore Zeolite that Selectively Adsorbs $\mathrm{H}_{2}$
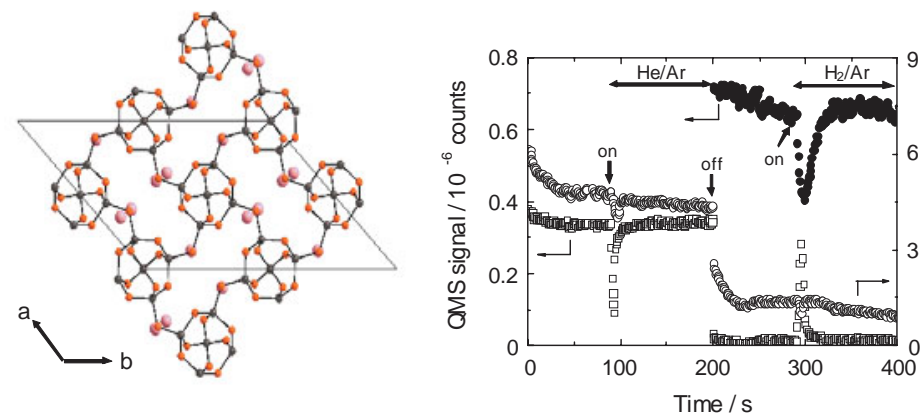

A synthetic potassium gallosilicate natrolite with $\mathrm{Si} / \mathrm{Ga}=1.28$ denoted PST-1 was found to selectively adsorb the smallest gases, especially $\mathrm{H}_{2}$, and hence to discriminate them from slightly larger molecules like $\operatorname{Ar}$ or $\mathrm{CO}_{2}$. Due to the remarkable easiness of its dehydration and great (hydro)thermal stability, PST-1 could be a potential candidate for fast, selective $\mathrm{H}_{2}$ and/ or He separation processes based on PSA or membrane technology. 


\section{Supporting Information}

for

Shin et al., "PST-1: A Synthetic Small-Pore Zeolite that Selectively Adsorbs $\mathbf{H}_{2} "$

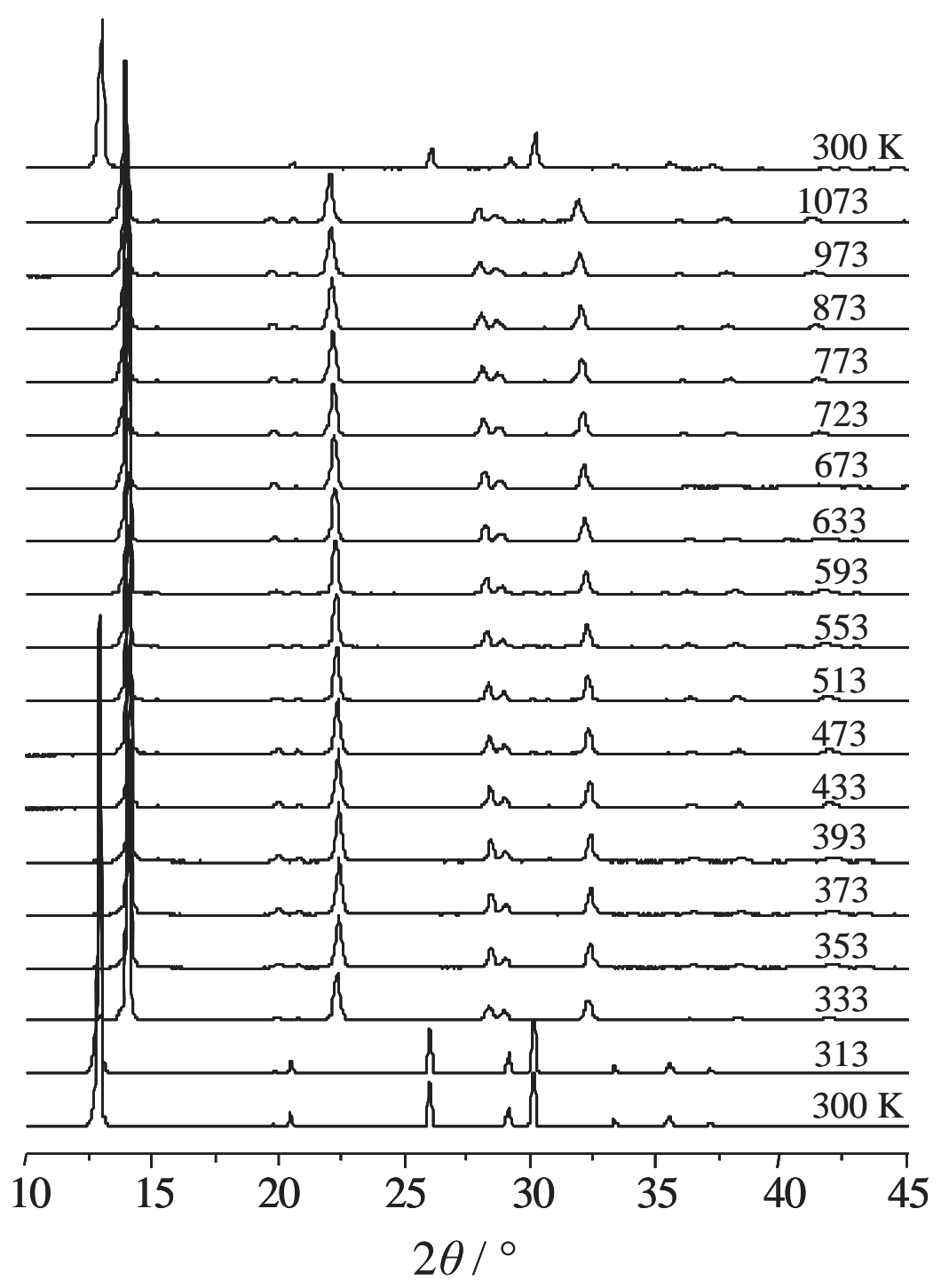

Figure 1S. Powder XRD patterns of PST-1 measured during in situ heating under vacuum to a residual pressure of $5 \times 10^{-3}$ Torr. The top trace is the pattern recorded after cooling from $1073 \mathrm{~K}$ to room temperature followed by exposure to ambient air for $0.5 \mathrm{~h}$. 

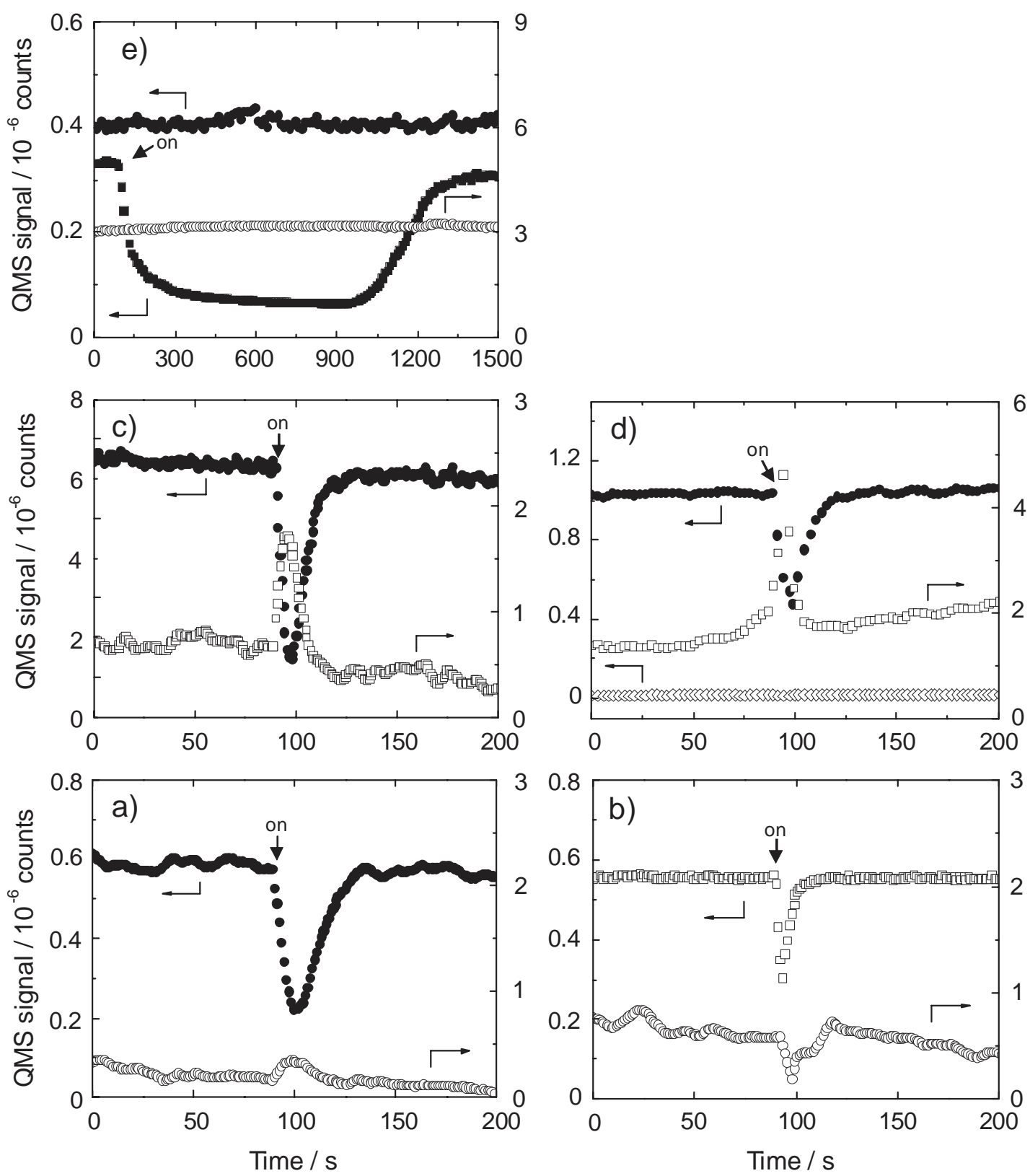

Figure 2S. Breakthrough curves of a) $\mathrm{H}_{2} / \mathrm{Ar}(4: 96 \mathrm{v} / \mathrm{v})$, b) $\mathrm{He} / \mathrm{Ar}(4: 96 \mathrm{v} / \mathrm{v})$, c) $\mathrm{H}_{2} / \mathrm{He}(4: 96$ v/v), d) $\mathrm{H}_{2} / \mathrm{CO}_{2} / \mathrm{He}(4: 4: 92 \mathrm{v} / \mathrm{v} / \mathrm{v})$, and e) $\mathrm{H}_{2} / \mathrm{H}_{2} \mathrm{O} / \mathrm{Ar}(2: 2: 96 \mathrm{v} / \mathrm{v} / \mathrm{v})$ gas mixtures over PST-1: $\mathrm{He}$, open squares; $\mathrm{H}_{2}$, closed circles; Ar, open circles; $\mathrm{CO}_{2}$, open diamonds; $\mathrm{H}_{2} \mathrm{O}$, closed squares. Mean value from triple parallel experiments (standard deviation $\sigma \leq 6 \%$ ) was adopted for each data point. 


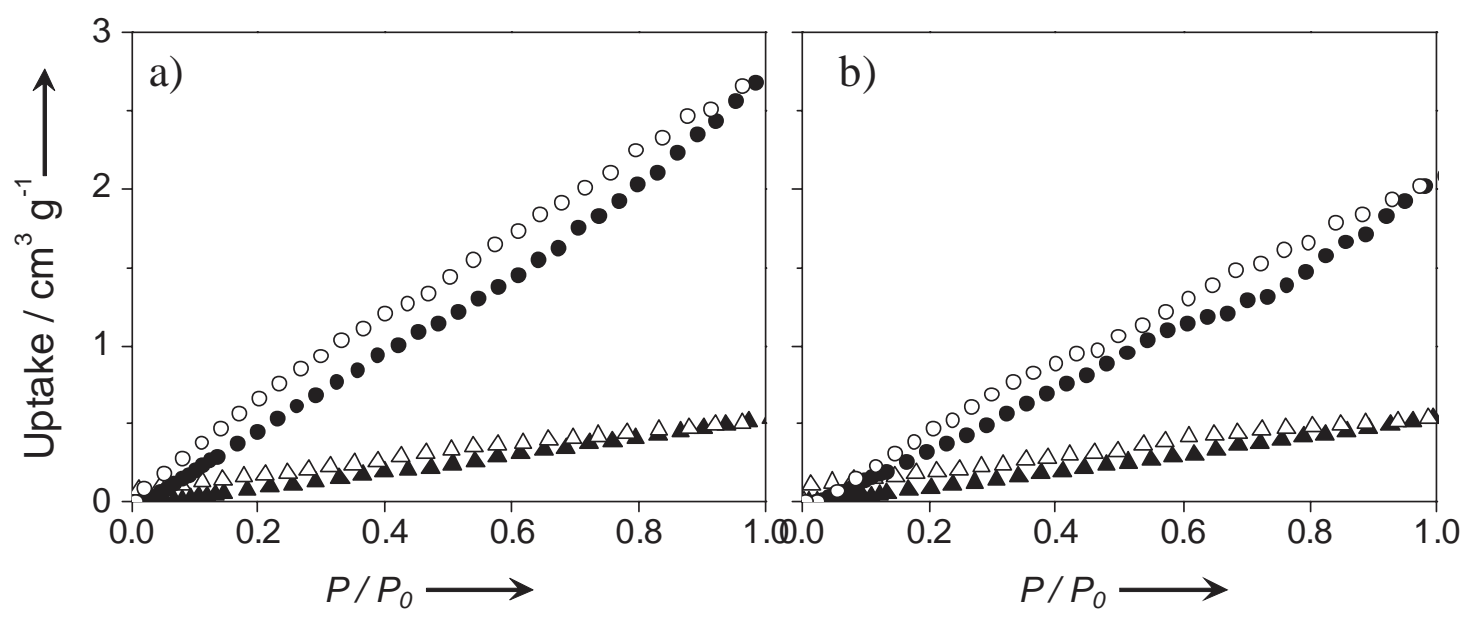

Figure 3S. a) $\mathrm{H}_{2}$ and b) $\mathrm{He}$ adsorption isotherms for PST-1 at $77 \mathrm{~K}$ (circles) and $303 \mathrm{~K}$ (triangles). The adsorption and desorption branches are marked by open and closed symbols. 


\section{Structure Analysis:}

Table 1S lists data collection and crystallographic parameters for the hydrated and dehydrated forms of PST-1. For as-made, hydrated PST-1, the synchrotron powder diffraction data was indexed in the space group $F d d 2$ with unit cell parameters $a=19.314 \AA$, $b=19.248$ $\AA, c=6.533 \AA$. The framework structure and the position of some of the $\mathrm{K}^{+}$cations were determined by direct methods using the program EXPO2004. ${ }^{[1]}$ The structure obtained in this way was further refined via the Rietveld method ${ }^{[2]}$ using the GSAS suite of programs, ${ }^{[3]}$ with restraints applied to T-O and O-O distances in the tetrahedral framework ( $1.70 \AA$ and $2.80 \AA$, respectively). Peak shape was modeled using the pseudo-Voigt profile function, ${ }^{[4]}$ and the Tsites were modeled as containing both $\mathrm{Ga}$ and $\mathrm{Si}$, initially with the ratio suggested by the chemical analysis. Difference Fourier analysis was applied to locate additional extra framework scattering. Although it was not possible to attribute this unambiguously to $\mathrm{K}^{+}$ions or water molecules, four likely sites for $\mathrm{K}^{+}$ions were located with reasonable distances to framework oxygen atoms (closest distances of approach 2.6-3.0 $\mathrm{A}$ ), accounting for 16 out of the measured 17.5 cations and residual electron density was attributed to extraframework water molecules (accounting for 12.7 molecules, three-fourths of the measured value of 16.7). The total amount of measured scattering is close to that expected from the composition. Allowing the $\mathrm{Ga}$ and $\mathrm{Si}$ occupancies to vary in the three T-sites, while maintaining full occupancy, suggested that site T1 might have a higher Ga content (ca. 50\%) than the other sites (ca. 30\% and 40\%, respectively), which was supported by the slightly longer average T1-O distance (1.73 $\AA$ cf. $1.66 \AA$ and $1.71 \AA$ for T2-O and T3-O). As seen in Table $1 \mathrm{~S}$, the final fit to the data was reasonable $\left(R_{\mathrm{wp}}=12.6 \%, R_{\mathrm{p}}=7.5 \%\right)$, although the pattern exhibited some anisotropic peak broadening.

For the PST-1 sample dehydrated at $373 \mathrm{~K}$, the unit cell was indexed as $F 112, a=17.717$ $\AA, b=17.634 \AA, c=6.532 \AA, \alpha=\beta=\gamma=90^{\circ}$. Comparison with the literature indicated the unit cell was similar to that of dehydrated sodium aluminosilicate natrolite $\mathrm{Na}_{2} \mathrm{Al}_{2} \mathrm{Si}_{3} \mathrm{O}_{10}{ }^{[5]}$ Taking the framework structure of this structure as a starting model, and converting to the more conventional space group setting $B 112$, the structure was refined assuming disordered $\mathrm{Si} / \mathrm{Ga}$ content of the tetrahedral sites and restraining $\mathrm{T}-\mathrm{O}$ and $\mathrm{O}-\mathrm{O}$ distances of the tetrahedra. $\mathrm{K}^{+}$ion positions were located by difference Fourier syntheses. The diffraction pattern showed anisotropic peak broadening that was difficult to model, but a reasonable fit was obtained to the observed pattern $\left(R_{\mathrm{wp}}=13.6 \%, R_{\mathrm{p}}=9.8 \%\right)$. The framework atom positions are similar to 
those of dehydrated aluminosilicate natrolite and 7.6 of the 8.8 expected extraframework $\mathrm{K}^{+}$ ions in the unit cell were located by difference Fourier analysis. The positions and occupancies of these cation sites were refined alternately to arrive at the final structure.

Table $2 \mathrm{~S}$ and $3 \mathrm{~S}$ lists the final atomic positions for the hydrated and dehydrated forms of PST-1, and their final Rietveld plots are displayed in Figure 4S, providing a good agreement of the observed and simulated powder diffraction patterns.

\section{Further Characterization:}

The powder XRD pattern (PANalytical X'Pert, $\mathrm{Cu} \mathrm{K}_{\alpha}$ radiation) and scanning electron micrograph (JEOL JSM-6300) of as-made PST-1 are given in Figure 5S. The XRD pattern of this gallosilicate material with needlelike crystal morphology can be indexed as orthorhombic and shows systematic absences consistent with space group $F d d 2$. A combination of inductively coupled plasma (Jarrell-Ash Polyscan 61E) and atomic absorption (Perkin-Elmer 5000) spectroscopies and thermal analyses (SII EXSTAR 6000) reveals that PST-1 has a unit cell composition $\mathrm{K}_{17.54} \mathrm{Ga}_{17.54} \mathrm{Si}_{22.46} \mathrm{O}_{80} \cdot 16.4 \mathrm{H}_{2} \mathrm{O}(\mathrm{Si} / \mathrm{Ga}=1.28)$.

The ${ }^{71}$ Ga MAS NMR spectrum (Bruker DSX 400 at $10 \mathrm{kHz}$ spinning rate, $0.1 \mathrm{~s}$ recycle delay, $122.040 \mathrm{MHz}, 1.0 \mu$ s pulse length) of PST-1 exhibits only one broad asymmetric line around $167 \mathrm{ppm}$, typical of framework tetrahedral Ga species, ${ }^{[6]}$ and its ${ }^{27} \mathrm{Si}$ MAS NMR spectrum (Bruker DSX 400 at $12 \mathrm{kHz}$ spinning rate, $40 \mathrm{~s}$ recycle delay, $79.490 \mathrm{MHz}, 2.0 \mu \mathrm{s}$ pulse length) is characterized by five ${ }^{29} \mathrm{Si}$ lines at $-76.5,-82.4,-88.4$, and -95.3 , and -100.4 ppm (Figure 6S). Attempts to deconvolute this spectrum by assuming each of the five $\operatorname{Si}(n \mathrm{Ga})$ lines with $n=4-0$ as a single $\mathrm{Si}$ environment gave a $(\mathrm{Si} / \mathrm{Ga})_{\mathrm{nmr}}$ ratio of 1.39 . Because this value are slightly higher than that (1.28) obtained from elemental analysis, it appears that the T-O-T angle range for the three crystallographically distinct T-sites of the NAT framework in space group $F d d 2$ is not narrow enough to get into a single ${ }^{29} \mathrm{Si}$ line envelope. Another possible explanation is the presence of Ga-O-Ga linkages in the PST-1 framework, violating the extended Loewenstein rule (i.e., avoidance of Ga-O-Ga species). Further work is in progress in order to elucidate the precise origin of the observed difference in the $\mathrm{Si} / \mathrm{Ga}$ ratios determined by elemental and ${ }^{27} \mathrm{Si}$ MAS NMR analyses. 
In situ high-temperature powder XRD experiments (Bragg-Brentano geometry, PANalytical X'Pert with Edmund Bühler HDK 1.4 attachment) show that PST-1 is already dehydrated at $333 \mathrm{~K}$ under vacuum to a residual pressure of $5 \times 10^{-3}$ Torr, while keeping the NAT topology. Furthermore, PST-1 is thermally stable at least up to $1073 \mathrm{~K}$, and the subsequent rehydration at room temperature of the completely dehydrated sample by exposure to ambient air for $0.5 \mathrm{~h}$ almost restores it to its original state. In situ XRD experiments were also performed in flowing $\mathrm{H}_{2}$ or $\mathrm{He}\left(100 \mathrm{~cm}^{3} \mathrm{~min}^{-1}\right)$ at room temperature after dehydration at $573 \mathrm{~K}$ under vacuum to a residual pressure of $5 \times 10^{-5}$ Torr for $1 \mathrm{~h}$.

[1] A. Altomare, R. Caliandro, M. Camalli, C. Cuocci, C. Giacovovazzo, A. Grazia, A. G. G. Moliterni, R. Rizzi, J. Appl. Crystallogr. 2004, 37, 1025-1028.

[2] H. M. Rietveld, J. Appl. Crystallogr. 1969, 2, 65-71.

[3] A. Larson, R. B. von Dreele, GSAS [General Structure Analysis System] Manual; Los Alamos Scientific Laboratory Report No. LA-UR-86-748; Los Alamos Scientific Laboratory: Los Alamos, NM, 1986.

[4] J. B. Hastings, W. Thomlinson, D. E. Cox, J. Appl. Crystallogr. 1984, 17, 85-95.

[5] W. H. Baur, W. Joswig Neues Jahrbuch fur Mineralogie: Monatsshefte, 1996, 171-187

[6] S. B. Hong, S.-H. Lee, C.-H. Shin, A. J. Woo, J. L. Alvarez, M. C. Zicovich-Wilson, M. A. Camblor, J. Am. Chem. Soc. 2004, 126, 13742-13751. 
Table 1S. Data collection and crystallographic parameters for PST-1.

\begin{tabular}{lll} 
Material & Hydrated PST-1 & Dehydrated PST-1 \\
\hline Formula & $\mathrm{K}_{0.88} \mathrm{Ga}_{0.88} \mathrm{Si}_{1.12} \mathrm{O}_{4} \cdot 0.82 \mathrm{H}_{2} \mathrm{O}$ & $\mathrm{K}_{0.88} \mathrm{Ga}_{0.88} \mathrm{Si}_{1.12} \mathrm{O}_{4}$ \\
Unit cell composition & $\mathrm{K}_{17.54} \mathrm{Ga}_{17.54} \mathrm{Si}_{22.46} \mathrm{O}_{80} \cdot 16.4 \mathrm{H}_{2} \mathrm{O}$ & $\mathrm{K}_{8.77} \mathrm{Ga}_{8.77} \mathrm{Si}_{11.23} \mathrm{O}_{40}$ \\
Formula weight of unit cell & 4114.8 & 1909.8 \\
Symmetry & Orthorhombic & Monoclinic \\
Space group & $F d d 2$ & $B 112$ \\
$a / \AA$ & $19.3148(2)$ & $17.7521(8)$ \\
$b / \AA$ & $19.2482(2)$ & $12.4705(5)$ \\
$c / \AA$ & $6.53311(5)$ & $6.53058(12)$ \\
$\alpha /{ }^{\circ}$ & 90 & 90 \\
$\beta /{ }^{\circ}$ & 90 & 90 \\
$\gamma /{ }^{\circ}$ & 90 & $135.0916(15)$ \\
$V / \AA$ & $1020.64(7)$ \\
Diffractometer & $2428.85(4)$ & $8 \mathrm{C} 2, \mathrm{PAL}$ \\
Temperature / K & $8 \mathrm{C} 2, \mathrm{PAL}$ & 373 \\
Wavelength / $\AA$ & 300 & 1.54220 \\
2 $\theta$ range / & 1.54220 & $10-85$ \\
Number of reflections & $10-90$ & 409 \\
Number of bond restraints & 272 & 52 \\
Total number of restraints & 30 & 58 \\
$R_{\mathrm{p}} / \%$ & 38 & 9.8 \\
$R_{\text {wp }} / \%$ & 7.5 & 13.6 \\
Ls shift/ su max & 12.6 & 0.06 \\
Ls shift/ su mean & 0.10 & 0.02 \\
\hline
\end{tabular}


Table 2S. Atomic coordinates and thermal parameters for as-made, hydrated PST-1.

\begin{tabular}{llllrc} 
Atom & \multicolumn{1}{c}{$x$} & \multicolumn{1}{c}{$y$} & \multicolumn{1}{c}{$z$} & Occupancy & $U_{\text {iso }}\left(\mathrm{x} 100 \AA^{2}\right)$ \\
\hline Si1 & $0.1683(1)$ & $0.1991(1)$ & $0.6384(10)$ & 0.491 & $3.29(8)$ \\
Ga1 & $0.1683(1)$ & $0.1991(1)$ & $0.6384(10)$ & 0.509 & $3.29(8)$ \\
Si2 & $0.0509(1)$ & $0.0820(2)$ & $0.6192(10)$ & 0.677 & $2.18(8)$ \\
Ga2 & $0.0509(1)$ & $0.0820(2)$ & $0.6192(10)$ & 0.323 & $2.18(8)$ \\
Si3 & 0.0 & 0.0 & $0.0070(12)$ & 0.585 & $2.10(9)$ \\
Ga3 & 0.0 & 0.0 & $0.0070(12)$ & 0.415 & $2.10(9)$ \\
O1 & $0.0577(3)$ & $0.0510(4)$ & $0.8613(15)$ & 1 & $2.42(9)$ \\
O2 & $0.0859(4)$ & $0.1605(4)$ & $0.6270(22)$ & 1 & $2.42(9)$ \\
O3 & $0.0898(4)$ & $0.0337(4)$ & $0.4468(17)$ & 1 & $2.42(9)$ \\
O4 & $0.2180(4)$ & $0.1582(4)$ & $0.8232(18)$ & 1 & $2.42(9)$ \\
O5 & $0.2055(4)$ & $0.1921(3)$ & $0.3931(16)$ & 1 & $2.42(9)$ \\
K1 & 0.1228 & 0.1257 & 0.1255 & $0.359(8)$ & 2.5 \\
K2 & 0.1600 & 0.0865 & 0.1275 & $0.284(6)$ & 2.5 \\
K3 & 0.2483 & 0.0196 & 0.5654 & $0.243(4)$ & 2.5 \\
K4 & 0.9650 & 0.2689 & 0.5663 & $0.086(5)$ & 2.5 \\
O101 & 0.1443 & 0.1101 & 0.1306 & $0.127(22)$ & 3.0 \\
O103 & 0.2853 & 0.0562 & 0.4993 & $0.136(12)$ & 3.0 \\
O104 & 0.1004 & 0.1542 & 0.1431 & $0.576(13)$ & 3.0 \\
\hline
\end{tabular}


Table 3S. Atomic coordinates and thermal parameters for dehydrated PST-1.

\begin{tabular}{llllrr} 
Atom & \multicolumn{1}{c}{$x$} & \multicolumn{1}{c}{$y$} & \multicolumn{1}{c}{$z$} & Occupancy & $U_{\text {iso }}\left(\mathrm{x} 100 \AA^{2}\right)$ \\
\hline Si1 & 0.0 & 0.0 & $0.0185(23)$ & 0.57 & $2.85(4)$ \\
Ga1 & 0.0 & 0.0 & $0.0185(23)$ & 0.43 & $2.85(4)$ \\
Si2 & 0.5 & 0.5 & $0.7647(23)$ & 0.57 & $2.85(4)$ \\
Ga2 & 0.5 & 0.5 & $0.7647(23)$ & 0.43 & $2.85(4)$ \\
Si3 & $0.3717(6)$ & $0.2962(8)$ & $0.3855(22)$ & 0.57 & $2.85(4)$ \\
Ga3 & $0.3717(6)$ & $0.2962(8)$ & $0.3855(22)$ & 0.43 & $2.85(4)$ \\
Si4 & $0.0637(5)$ & $0.1979(8)$ & $0.6336(21)$ & 0.57 & $2.85(4)$ \\
Ga4 & $0.0637(5)$ & $0.1979(8)$ & $0.6336(21)$ & 0.43 & $2.85(4)$ \\
Si5 & $0.1330(6)$ & $0.0687(8)$ & $0.3981(21)$ & 0.57 & $2.85(4)$ \\
Ga5 & $0.1330(6)$ & $0.0687(8)$ & $0.3981(21)$ & 0.43 & $2.85(4)$ \\
Si6 & $0.4252(60$ & $0.5542(7)$ & $0.1511(21)$ & 0.57 & $2.85(4)$ \\
Ga6 & $0.4252(60$ & $0.5542(7)$ & $0.1511(21)$ & 0.43 & $2.85(4)$ \\
O1 & $0.1125(7)$ & $0.1008(14)$ & $0.1592(23)$ & 1 & $2.85(4)$ \\
O2 & $0.4130(8)$ & $0.4811(16)$ & $0.9152(23)$ & 1 & $2.85(4)$ \\
O3 & $0.2500(7)$ & $0.1140(12)$ & $0.3962(32)$ & 1 & $2.85(4)$ \\
O4 & $0.1381(9)$ & $0.3889(11)$ & $0.6423(33)$ & 1 & $2.85(4)$ \\
O5 & $0.1518(11)$ & $0.1910(15)$ & $0.5628(26)$ & 1 & $2.85(4)$ \\
O6 & $0.443498)$ & $0.2971(14)$ & $0.2039(26)$ & 1 & $2.85(4)$ \\
O7 & $0.9608(8)$ & $0.1148(12)$ & $0.4692(27)$ & 1 & $2.85(4)$ \\
O8 & $0.3563(11)$ & $0.4131(13)$ & $0.3369(25)$ & 1 & $2.85(4)$ \\
O9 & $0.0112(12)$ & $0.1231(14)$ & $0.8729(23)$ & 1 & $2.85(4)$ \\
O10 & $0.4332(11)$ & $0.3424(10)$ & $0.6200(25)$ & 1 & $2.85(4)$ \\
K1 & 0.5842 & 0.3506 & 0.6327 & $0.387(9)$ & 2.0 \\
K2 & 0.3458 & 0.5952 & 0.6641 & $0.613(9)$ & 2.0 \\
K3 & 0.2512 & 0.1245 & 0.8790 & $0.916(6)$ & 2.0 \\
\hline
\end{tabular}



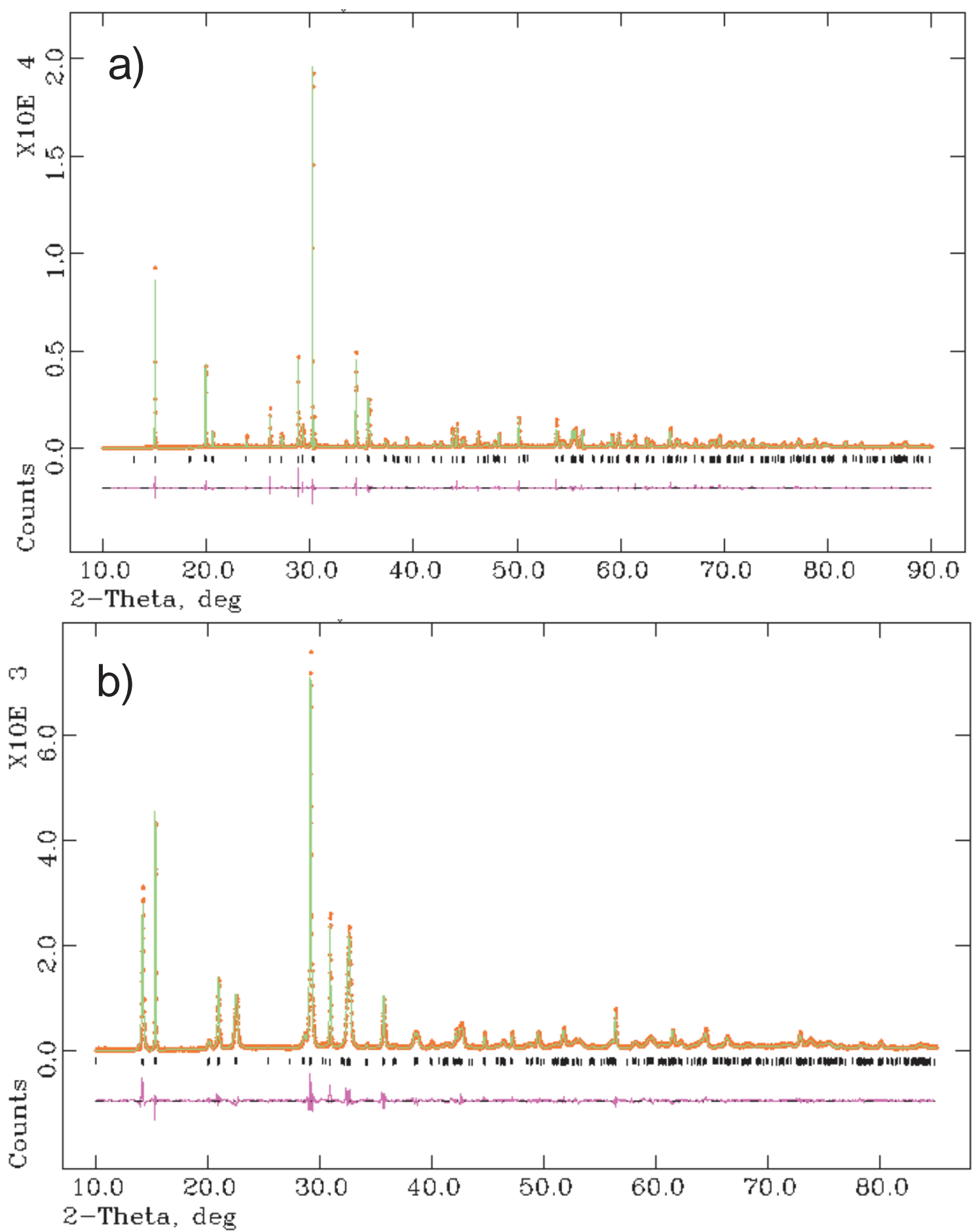

Figure 4S. Rietveld plots for the a) hydrated and b) dehydrated forms of PST-1: observed data (crosses), calculated profile (solid line), and difference (lower line). Vertical ticks indicate the positions of allowed reflections. 


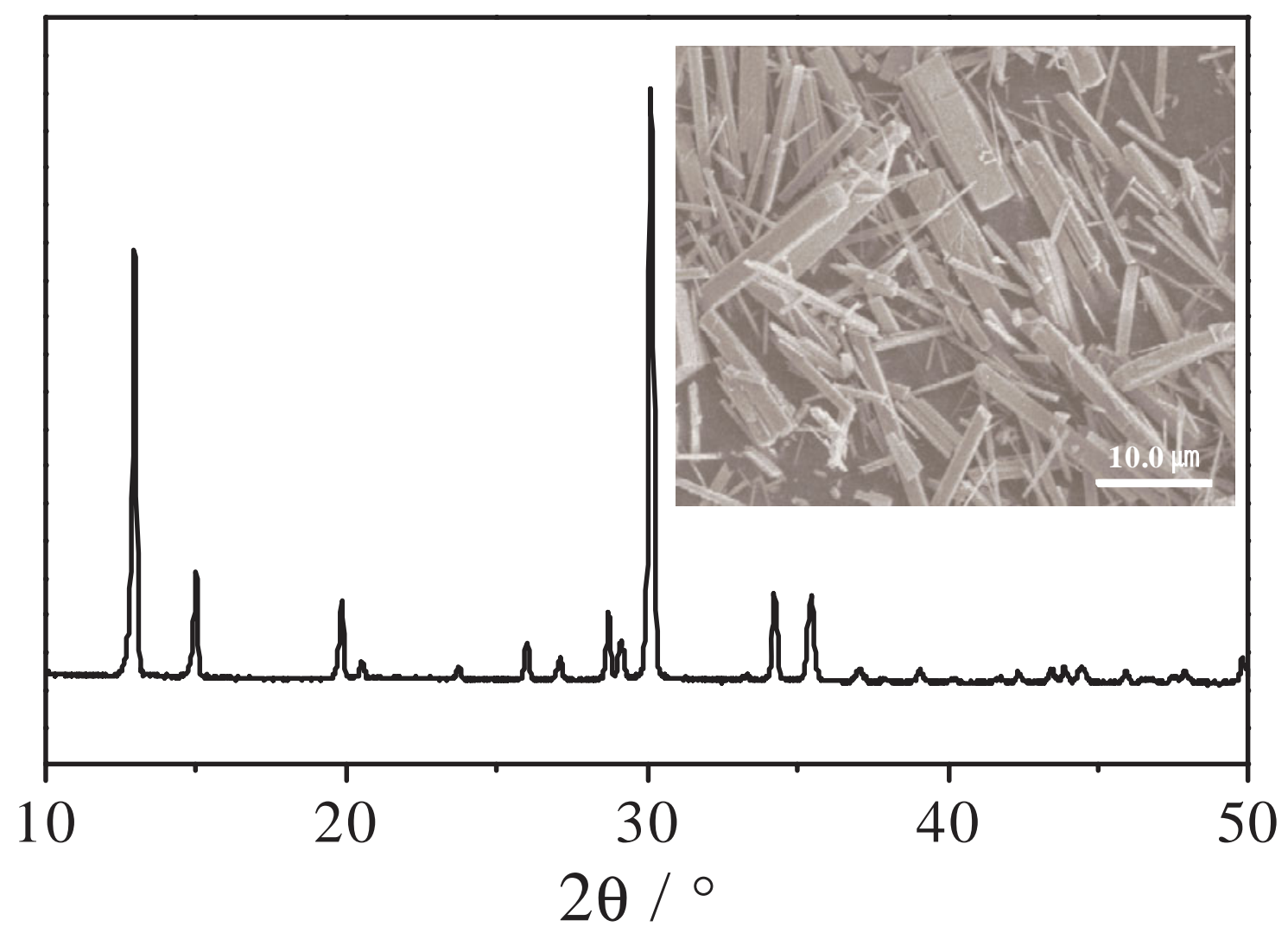

Figure 5S. Powder XRD pattern and SEM image of as-made PST-1. 

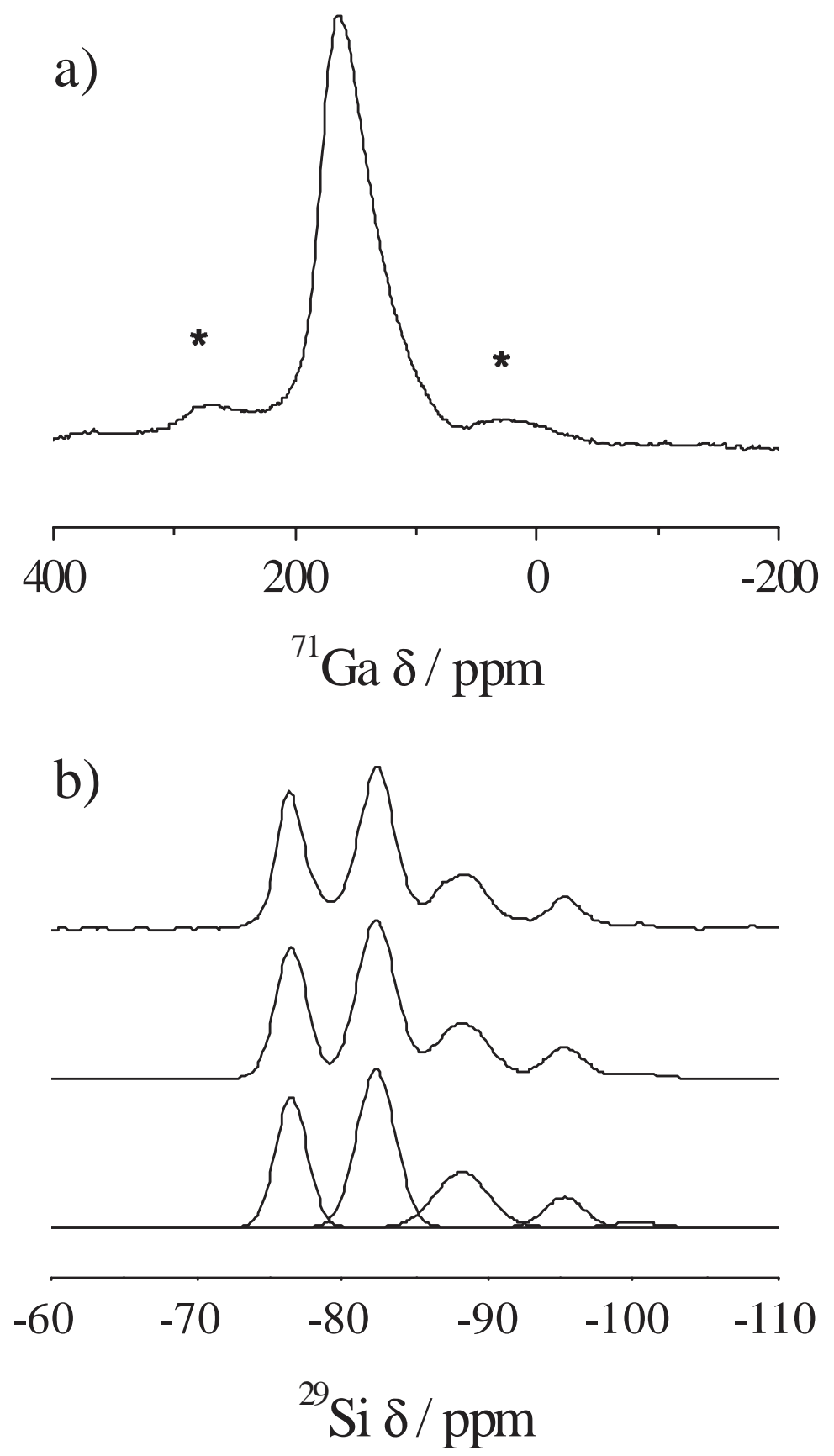

Figure 6S. a) ${ }^{71}$ Ga MAS NMR spectrum of PST-1. Spinning side bands are marked by asterisks. b) ${ }^{29} \mathrm{Si}$ MAS NMR spectrum of PST-1: experimental (top); simulated (middle); deconvoluted components (bottom). 